\title{
INVESTIGATING THE EFFECTIVENESS OF CORPORATE GOVERNANCE CODE REVISIONS ON THE PERSPECTIVE OF THE REVISION INTERVAL
}

\author{
Abdul Hadi Zulkafli \\ Universiti Sains Malaysia \\ Chee-Wooi Hooy \\ Universiti Sains Malaysia \\ Chai-Aun Ooi* \\ Universiti Sains Malaysia
}

\begin{abstract}
This study investigates the effectiveness of corporate governance code revisions on firm value using 35 countries' public listed firms over 2007-2014. First, this study finds that progressive code revisions have significant positive relationship with firm value. Second, this study finds that the interval of corporate governance code revision is significant to influence the effectiveness of code revisions. Further analysis reveals that the relationship between code revision interval and firm value is non-linear, which is depicted in inverted U-shaped. The findings suggest that a moderate code revision interval, i.e. 4 years once is optimal to maximize firm value. In overall, the findings of this study have suggested several practical implications to the development of the national codes of corporate governance.
\end{abstract}

Keywords: Code; Corporate Governance; Revision; Interval; Cost; Firm Value.

\section{INTRODUCTION}

Globalization has forced the convergence of local corporate governance (CG) best practices towards the dominant international model (Becht, Bolton and Roell, 2003; Cuervo, 2002; Hansmann and Kraakman, 2004). Diffusion of the best practices is more than driven by legitimation reason instead of aiming to improve the standard of CG (Zattoni and Cuomo, 2008). Such legitimation lies on the national codes of CG which are not mandate by laws, but have played the role to fill the deficiencies of the rigid legal CG laws (Aguilera and Cuervo-Cazurra, 2004). Previous studies like Drobetz et al. (2004), Beiner et al. (2006), Goncharov et al. (2006), Henry (2010), and Munisi \& Randøy (2013) found that complying with the national codes of $\mathrm{CG}$ brings a significant positive effect on firm value. It implies that the national codes of CG have been taken as the important reference to individual firm's CG practices.

For un-mandatory national codes of $\mathrm{CG}$, it can be easily revised without to have undergoing complicated legal processes. Revisions of the codes of CG (henceforth code revision) tend to improve the quality of governance guidance, while incorporating new practices of governance expected by the markets. Upon compliance with the revised codes of CG, the cost required may influence firms' degree of compliance.

\footnotetext{
- Corresponding author: Chai-Aun Ooi, School of Management, Universiti Sains Malaysia, 11800 USM, Penang, Malaysia. Email: wilson.usmfinance@gmail.com
} 
Limited evidences from the previous studies show the effect upon the cost of compliance with a code of CG towards firm value, although the relationship between degree of compliance and firm value has been well established. The lack of evidences may be due to the difficulty to obtain data on the cost of compliance. Hence, it remains a research gap of investigation.

Upon un-access to the cost of compliance, this study argues that the interval of CG code revisions is proportional to the cost of compliance. On one hand, short interval of CG code revisions can increase the cost of compliance because firms need to frequently revise and adapt its' corporate governance settings to the new changes. Also, short interval of revisions provides insufficient time of compliance which may hamper efficient diffusion of the best practices to the firms. On the other hand, long CG code revision interval is usually accompanied with massive accumulated new practices which can hamper firms to efficiently adopt all of the new guidance. Also, massive restructuring may reduce the degree of compliance. In short, the interval of revisions may be a complicated element in affecting the effectiveness of $\mathrm{CG}$ code revisions. This study raises the concern about non-linear relationship between CG code revision interval and firm value, by arguing that a moderate interval of revision can optimally increase the effectiveness of CG code revision.

This study tends to fill the research gap by associating the interval of CG code revisions to firm value. Firm value is investigated because it is claimed that better CG mechanism driven by a good CG guidance can reduce the cost of agency, or improve the value of shareholders. In this context, it can demonstrate whether the revisions of CG codes are effective to meet the objective of agency cost reduction. In overall, the relationship between CG code revision interval and firm value can reveal whether the revision interval is affecting the effectiveness of CG code revisions. This study uses the sample from 35 countries over 2007-2014. Time series data allows the present study to track more than one code revisions in the sample countries. Preliminary analysis finds that some countries revise the codes of CG in constant interval, while some countries do not have constant revision interval. The heterogeneous interval of CG code revision show the worthy of research.

The research of this study is based on institutional theory which lies on the organization legitimacy. Institutional theory demonstrates the role of states, professional bodies and public opinions in shaping organizational structures, policies, and the way a firm responds to such external influence so that to obtain the support and legitimacy (Scott, 1995). Goncharov et al. (2006) denote that the markets have exerted pressure to the firms on complying with the national codes of CG due to legitimacy. The markets are expected to monitor firms' CG in accordance with the principle and practices of the national codes of CG. Goncharov et al. (2006) shows that market pressure on firm compliance is arisen through stock valuation, where lower valuation is given to the firms which fail to comply with the code without justification. Therefore, market pressures drive the firms to comply with the un-mandate codes of CG, even the cost of compliance is incurred to the firms.

In summary, the findings of this study implies that the firms' capability is a key element to influence the effectiveness of CG code revisions. This study adds to the literature that practicing a good corporate governance system may not be completed if the firms face financial and non-financial burden to adopt the best practices of governance. This study indicates that the regulators should take into account the newly revised practices of governance is applicable in the context of the local corporations, even though when the developed countries have adopted such practices. Unsuitable guidance may drive firms to bear a great burden of compliance, or it may lead to symbolical compliance than adopting the new practices substantively. This study highlights the art of managing CG code revisions, and suggests the optimal interval of code revisions in order to maximize firm value. 


\section{LITERATURE REVIEW}

\subsection{The Development of the National Codes of CG}

CG institutional framework are significant to reduce the efficiency of expropriation technology used by the insiders (La Porta et al., 2000). However, amending or imposing the new CG laws involves a complicated process, and it is time-consuming. To overcome it, a soft law of CG is tailored, which is the national code of CG. The code is not mandate by law, but due to invisible pressure given by the markets to the firms for compliance with the code, hence, it is able to complement with the legislative and regulatory institutional framework of CG (Aguilera and Cuervo-Cazurra, 2004).

The first national code of CG was released in 1970s following the wave of mergers and hostile takeovers. The initial report namely The Role of Composition of the Board of Directors of the Large Publicly Owned Corporation was published by the U.S. Business Roundtable in 1978. The report drove a shift on the role of the board of directors from being largely ornamental to one with substantial responsibilities (Aguilera and Cuervo-Cazurra, 2004). By the late 1980s, the number of countries issuing individual national code of CG raised. Hong Kong Stock Exchange issued its national code of best practices in 1989, and it was followed by Ireland in 1991. The Cadbury Report was then released in the U.K in 1992, and it gave impetus to a wave of evolution on worldwide CG through inducing an exponential rise in the number of national code of CG (Aguilera and Cuervo-Cazurra, 2004).

Voluntarily compliance with the code of CG was originally applied in British Cadbury Report. It was based on "comply or explain" principle, where firms were required to comply with the CG best practices whichever appropriate and suitable. However, firms need to provide explanations for the part of noncompliance. In this context, it is presumed that the markets will closely monitor the firms' compliance with the code (Maassen et al, 2004). Maassen et al. (2004) have claimed that self-regulation principle has brought a significant positive impact towards the development of codes of CG in the world. Consistently, Goncharov et al. (2006) show that firms which fail to comply with the code of CG will be penalized by the markets by lowering the valuation through stock prices, unless the non-compliance is justified (Anand, 2005). This has explained why voluntarily compliance principle is still implemented until today (Erhardt and Nowak, 2002).

Given compliance with the codes of CG has been monitored by the markets, firms need to response to the release of the code of CG. The previous studies like Conyon and Mallin (1997) and Weir and Laing (2000) find that there is a large extent of compliance with the Cadbury Report. Pellens, Hillebrandt and Ulmer (2001) conduct a survey with the corporations of DAX100 and find that 95.6 percent of the corporations agree with the regulation of the national code of CG, and 48.5 percent of the firms have full compliance with it. The studies indicate that the national codes of CG have become a legitimacy to the corporations.

For issuing the code of CG is not a one-time effort, but it needs to be revised to increase the degree of acceptance and to incorporate the new practices of governance. As documented by the chairperson of Australian CG Council, Karen Leslie Hamilton, in the Principles of Good CG and Best Practice Recommendations released in year 2003, documenting that the Code is not the final and complete guidance (Australian Stock Exchange, 2003). The Norwegian CG Board (2014) documents that the reasons for requiring a revised Norwegian Code of Practice for $C G$ include changes in legislation and regulations as well as the experience gained from the use of the Code, also due to the changes of international CG guidance. 
Majority of the countries have conducted a series of effort on CG code revision. For example, in the United Kingdom, the first CG Code namely Cadbury Report is developed in 1992. The Cadbury Code is then replaced by a newly revised code of CG in year 2003, namely The Combined Code. The Code is revised again in year 2006, 2008 and 2009. In order to meet the changing environment due to the new Listing Regime introduced in 2010, the U.K. Financial Reporting Council released a new CG Code namely The UK CG Code in year 2010, and the Code was revised in 2012 and 2014. Developing countries also revise their earlier code of CG. For example, in Malaysia, the first release of Malaysian Code on CG in 2000 was revised in 2007 and 2012. In Thailand, the Stock Exchange of Thailand releases the first code of CG namely The SET Code of Best Practices for Directors of Listed Companies in 1998, and made a series of revision in 1999, 2002, 2006, and 2012, respectively.

CG code revisions give the improved CG guidance to the firms. For example, the recent revised Malaysian Code of Corporate Governance in 2012 (MCCG) emphasized the responsibility of the board to formalize ethical standards through a code of conduct, and ensure its compliance. Also, the MCCG 2012 additionally emphasized on the responsibility of the board to monitor the company's strategies are parallel with corporate sustainability growth (The Security Commission Malaysia, 2012). Another example is shown in The Norwegian Code of Practice for Corporate Governance revised in 2014. The Code had made the changes on several aspects of governance, including the aspect of equity and dividends, the role and structure of nomination committee, the matter of corporate assembly and the structure of board of directors with respects to composition and independence, and remuneration of executive personnel (The Norwegian Corporate Governance Board, 2014). Although no empirical evidences are found in the literature showing code revisions significantly improve firm value, however, this study hypothesizes that the improved CG guidance should improve the efficiency of CG and bring positive effect on firm value.

Hypothesis 1: Cumulative number of CG code revision has significant positive relationship with firm value

Zattoni and Cuomo (2008) shows that a real diffusion of the code of CG may need to be modified or reinvented by the firms before it could be adopted. It implies that firms need to spend the resources to adopt and adapt the new best practice of governance, hence complying with the codes of CG requires implementation costs (Aguilera, Filatotchev, Gospel and Jackson, 2008). Doidge, Karolyi and Stulz (2007) document that the costs of compliance with good CG include out-of-pocket costs of acquiring better governance mechanisms and the cost in time or effort allocation. For example, it is time consuming to seek for high quality external auditor, and reputable independent directors require higher compensation and limit managerial discretion. Given complying with a better CG practice is costly, it may harm firm value if the new practices does not add value to the firms. Neither of the previous studies provide empirical evidences to show whether the cost of compliance with a code of CG is significant to affect firm value. For the cost of compliance is unusual to be revealed to the shareholders, there is no way to assess the cost of compliance directly. However, the interval of CG code revisions may shed light the matter of cost of compliance. The rationale is that, short interval of revision drive firms to adapt to new practices frequently, and increase the cost of CG restructuring, while long interval of revision drive firms to comply with massive accumulated new practices. Weir and Laing (2000) show that full compliance with Cadbury Report does not bring better firm performance than partial compliance or non-compliance. Although the underlying reason of such result is yet to be investigated, it may link to the matter of the cost of compliance. Even, Munisi \& Randøy (2013) show that compliance with SubSahara Africa code of CG has negative influence on firm value; the result might link to high cost of compliance which the practices of governance causing high opportunity cost incurred to other potential 
investment. Hence, the interval of code revisions which are related to the cost of compliance is hypothesized to have significant relationship with firm value.

Hypothesis 2: The interval of CG code revisions has significant relationship with firm value.

This study further argues that the effect of CG code revision interval on firm value is non-linear. This is because, excessively long revision interval may leave the firms behind the world's changing CG expectations, and it may incur extraordinary high cost of compliance for the large number of accumulated new best practices. In such case, firms may reluctant to fully comply with the massive accumulated new best practices, but only comply selectively within their capability. These firms may explain to the shareholders for the part of non-compliance due to limited firms' resources and governing facilities. In the opposite, excessively short revision interval may also increases the cost of compliance, because firms need to restructure their governance model frequently. Also, with overly short revision interval, firms may reluctant to adapt to the fast changing governance best practices. Hence, a moderate CG revision interval may only be optimal to improve firm value.

Hypothesis 3: The effect of CG code revision interval on firm value is non-linear.

\section{DATA}

This study selects 35 countries which have issued the national code of CG, including Australia, Austria, Belgium, Brazil, Canada, China, Denmark, Egypt, Finland, France, Germany, Hong Kong, Hungary, India, Indonesia, Israel, Italy, Japan, Korea, Malaysia, Netherlands, Norway, New Zealand, Philippines, Poland, Portugal, Russia, Singapore, South Africa, Sweden, Switzerland, Taiwan, Thailand, Turkey, and United Kingdom. This study excludes the codes of CG designed for certain investor profiles such as institutional investors, insurance brokers, managers in financial institutions, and etc. The codes of CG from the U.S. are excluded in this study, for the U.S. codes of CG are mandate by laws, epitomized by Sarbanes-Oxley Law, which is different with majority of the codes of CG in the other countries emphasizing on voluntarily compliance principle. The data on CG code revisions is obtained from European CG Institute (ECGI).

CG score of individual firm was extracted from ASSET4 ESG. The sample of this study is limited by the data availability from ASSET4 ESG. Initially, the sample of this study is comprised of public listed companies across forty-eight economies in the world. This study excludes the sample of seven economies due to low data coverage; this study also excludes another six economies which do not release the national code of CG. Ultimately, the sample of this study covers thirty-five economies, comprising of twenty-one developed countries and thirteen developing countries based on the definition of WorldBank. The other data on firm fundamental variables such as total assets, leverage, market-tobook value, return on assets and firm age are obtained from Datastream, a division of Thomson Reuters. The period of analysis in this study is 2007-2014. The sample period begins from 2007 due to data limitation from ASSET4 ESG prior to 2007. Nonetheless, eight years of time span in the analysis is sufficient to capture several CG code revisions in majority of the countries. 


\section{RESEARCH METHODOLOGY}

\subsection{The Models}

Model 1 is developed to investigate the relationship between cumulative number of CG code revision and firm value.

$$
\begin{aligned}
{\text { AdjTobin } Q_{i j t}=} & \alpha_{i j t}+\beta_{1} \text { FirmSize }_{i j t}+\beta_{2} \text { Leverage }_{i j t}+\beta_{3} \text { MTBV }_{i j t}+\beta_{4} \text { ROE }_{i j t}+\beta_{5} \text { CGSCore }_{i j t} \\
& +\beta_{6} \text { Cumulative Re vision }_{i t}+\varepsilon_{i j t}
\end{aligned}
$$

Tobin's Q is the market value of equity plus book value of liabilities divided by book value of equity plus book equity of liabilities for firm $i$ in country $j$ at year $t$. Adj_Tobin $Q$ is the adjusted Tobin's Q by deducting the mean value of Tobin's $Q$ within the period of compliance with the latest code of CG by firm $i$ in country $j$ at year $t$. The adjusted Tobin's Q aims to solve the problem upon the delay effect of adopting the new best practice of CG on firm value. This study chooses to use market-based firm value because the effect of compliance with a new code of CG may not immediately and directly associated with accounting performance such as return on assets; instead, market-based firm value is more relevant given the markets monitor firm compliance through valuing the stock prices, as shown by Goncharov et al. (2006). Fernández-Rodríguez, Gómez-Ansón and Cuervo-García (2004) supports the view that the markets have foreseen the positive abnormal stock returns from adopting the best practice of CG.

The control variables of regression include: firm size (FirmSize) which is the natural logarithm of total asset of firm $i$ in country $j$ at year $t$, leverage (Leverage) which is the natural logarithm of total asset of firm $i$ in country $j$ at year $t$, market-to-book value $(M T B V)$ whch is the ratio of market value to book value of the equity of firm $i$ in country $j$ at year $t$, return on equity $(R O E)$ which is the net income divided by total equity of firm $i$ in country $j$ at year $t$. These variables are widely used as the control variables in CG studies. The data were obtained from Datastream. Also, the regression controls for firms' CG score (CGScore) which composed from several CG sub-scores namely board function index, board structure index, shareholder right protection index and compensation policy index. based on ESGASSET4. The cumulative number of CG code revision (CumulativeRevision) is the total number of the code of CG released for firm $i$ in country $j$ at year $t$ since the first issue, according to Europoean Corporate Governance Institute.

Model 2 is developed to investigate the relationship between the interval of CG code revisions and firm value, while the other control variables remain. Non-linear effect of the interval of CG code revisions are investigated, as shown in model 3. The squared term of Interval_Revision ${ }_{i t}$ is incorporated in the model, and the level of significant, as well as the sign of the coefficient of the square term are observed.

$$
\begin{gathered}
{\text { AdjTobin } Q_{i j t}=}_{\alpha_{i j t}+\beta_{1} \text { FirmSize }_{i j t}+\beta_{2} \text { Leverage }_{i j t}+\beta_{3} M T B V_{i j t}+\beta_{4} \text { ROE }_{i j t}} \\
+\beta_{5} \text { CGScore }_{i j t}+\beta_{6} \text { Interval_Revision }_{i t}+\varepsilon_{i j t}
\end{gathered}
$$

Interval_Revision $i j$ represents time interval between the current CG code revision and the previous revision. 


\subsection{Results and Discussions}

Table 1 shows the descriptive statistics on the control variables. Firm size (FirmSize) has positive mean value of 17.34, with the standard deviation is 2.98 . The median of firm size is close to the mean value, indicating the sample does not have extreme value. Leverage (Leverage) has mean value of 0.17 , with the minimum and maximum is 0 and 2.70. It shows that some firms in the sample are fully financed by equity. The overall firms in the sample are not positioned in high level of financial risk. A positive mean and median value of market-to-book $(M T B V)$ is shown in the table, i.e. 2.53 and 1.67, respectively, implying majority of the firms have positive growth opportunities. Some firms in the sample face lower than expected valuation by the markets, which is shown in negative $M T B V$. Return on equity $(R O E)$ has mean value of 0.13 , with the standard deviation of 0.23 . The minimum value of $R O E$ is -0.96 , implying a consistent view that some firms in the sample suffer an extremely low valuation by the markets due to its poor return on equity, while majority of the sample has positive return on equity. Adj_Tobin $Q$ has mean value of 1.63 , with the minimum and maximum values are 1.01 and 9.30 respectively. The mean of CumulativeRevision is 3.81 , with standard deviation of 2.02 , with the minimum and maximum are 0 and 12 respectively. The average interval of CG code revision (Interval_Revision) is 4.28 years, or median of 4 years. Zero year of interval shown in the minimum value of Interval_Revision is because some of the countries release the codes of CG only after the beginning of the sample period of this study.

Table 1: Descriptive Statistics of Firms' Fundamental Variables

\begin{tabular}{ccccccccc}
\hline \hline \multirow{2}{*}{ Variable } & \multirow{2}{*}{ Obs. } & \multirow{2}{*}{ Mean } & \multirow{2}{*}{ Std. Dev. } & \multicolumn{5}{c}{ Quantiles } \\
\cline { 5 - 8 } & & & & Min. & $\mathbf{0 . 2 5}$ & Median & $\mathbf{0 . 7 5}$ & Max. \\
\hline FirmSize & 21180 & 17.34 & 2.98 & 10.82 & 15.04 & 17.04 & 19.5 & 25.69 \\
Leverage & 21175 & 0.17 & 0.17 & 0.00 & 0.03 & 0.14 & 0.26 & 2.70 \\
Market-to-Book & 20033 & 2.53 & 3.40 & -3.73 & 1.05 & 1.67 & 2.81 & 32.47 \\
ROE & 20599 & 0.13 & 0.23 & -0.96 & 0.05 & 0.12 & 0.20 & 1.50 \\
Adj_Tobin's Q & 20541 & 1.63 & 1.16 & 0.56 & 1.01 & 1.23 & 1.77 & 9.30 \\
CGScore & 18697 & 0.44 & 0.30 & 0.01 & 0.14 & 0.43 & 0.73 & 0.97 \\
CumulativeRevision & 24663 & 3.81 & 2.02 & 0.00 & 2.00 & 3.00 & 5.00 & 12.00 \\
Interval_Revision & 23902 & 4.28 & 2.13 & 0.00 & 3.00 & 4.00 & 5.00 & 12.00 \\
\hline \hline
\end{tabular}

In Table 2, firm size shows a negative relationship with firm value, with the estimate of -0.28 which is significant at 1 per cent level. It suggests that increasing firm size brings negative firm value. Also, leverage shows a negative relationship with firm value which is significant at 1 per cent level. This has indicated that majority of the firms do not efficiently utilize debt financing to maximize firm value. However, market-to-book has significant positive relationship with firm value, with the estimate of 0.0724 significant at 1 per cent level. This is consistent with return of equity showing a positive relationship with firm value at 1 per cent level. In sum, the estimates of the control variables show consistent with the previous studies. CG score does not show any significant relationship with firm value, although CG has been proved significantly related to firm value in the literature. For CG score captures the overall practices of CG instead of single aspect of CG, it reflects the overall CG mechanisms are less efficient to improve firm value. Firms may only focus to improve single aspect of CG while have ignored the other aspects of CG. It creates a loophole for enhancing firm value when opportunism occurs through the other channel of CG.

Highlighting the estimate of cumulative number of code revision, it shows a positive relationship with firm value, i.e. 0.0564 at 1 per cent level of significance. The result indicates that every code revision increases firm value by 0.0564 . In other words, progressive CG code revisions bring betterment on firm value. It gives a direct implication that $\mathrm{CG}$ code revisions are effective to improve firm value 
significantly. The results are supported by Henry (2010), Kouwenberg (2008), Garay and González (2008), Beiner et al. (2006), and Drobetz et al. (2004) showing that compliance with a particular CG code has positive influence on firm value, although these studies do not shed light on progressive code revisions. This has confirmed that the effort of code revisions are viewed positive to tackle the problem of agency.

Table 2: Regression Results of the Relationship between Cumulative Number of CG Code Revision and Firm Value

\begin{tabular}{cc}
\hline \hline & MeanAdj_Q \\
\hline FirmSize & $-0.2805^{* * * *}$ \\
Leverage & $(0.0000)$ \\
& $-0.6069^{* * *}$ \\
Market-to-Book & $(0.0000)$ \\
& $0.0724^{* * *}$ \\
ROE & $(0.0000)$ \\
& $0.2466^{* * *}$ \\
CGScore & $(0.0000)$ \\
& 0.0346 \\
Cumulative_Revision & $(0.4545)$ \\
& $0.0564^{* * *}$ \\
Constant & $(0.0000)$ \\
& $4.5259^{* * *}$ \\
Firm Fixed Effect & $(0.0000)$ \\
Observations & Yes \\
Adjusted R & 16214 \\
\hline \hline
\end{tabular}

Notes: $*, * *$, and $* * *$ represent the level of significance at $1 \%, 5 \%$ and $10 \%$ respectively. The numbers inside parentheses are pvalues.

This study further examines individual effect of the recent CG code revisions on firm value, instead of looking at the cumulative number of $\mathrm{CG}$ code revisions. The effects of individual effort of revision are represented by dummy variables, i.e. D_Revision1, D_Revision2, D_Revision3, D_Revision4 and D_Revision5. Preliminary analysis has revealed a maximum of 6 code revisions contains in the sample, but this study only includes the maximum of 5 rounds of revisions because the $6^{\text {th }}$ revision is only performed by a single country among 35 countries of the total sample. Table 3 reports the results of regressions. The results show an increasing pattern on the positive estimates from the earlier revision to the recent revision. It confirms that progressive $\mathrm{CG}$ code revisions bring better firm value.

Table 3: Regression Results of the Relationship between CG Code Revision Intervals and Firm Value

$\begin{array}{cc}\text { FirmSize } & -0.2784 * * * \\ & (0.0000) \\ \text { Leverage } & -0.6405 * * * \\ & (0.0000) \\ \text { Market-to-Book } & 0.0732 * * * \\ \text { ROE } & (0.0000) \\ & 0.2400 * * * \\ \text { CGScore } & (0.0154) \\ & 0.0548 \\ & (0.2372)\end{array}$


Table 3: Regression Results of the Relationship between CG Code Revision Intervals and Firm Value (cont.)

\begin{tabular}{cc}
\hline D_Revision1 & $0.0869^{* * *}$ \\
D_Revision2 & $(0.0000)$ \\
& $0.1811^{* * *}$ \\
D_Revision3 & $(0.0000)$ \\
& $0.1845^{* * *}$ \\
D_Revision4 & $(0.0000)$ \\
& $0.1590^{* * *}$ \\
D_Revision5 & $(0.0000)$ \\
& $0.1591^{* * *}$ \\
Constant & $(0.0010)$ \\
& $4.5948^{* * *}$ \\
& $(0.0000)$ \\
\hline Standard Errors clustered by & Robust \\
Observations & 16235 \\
Adjusted R & 0.7857 \\
\hline \hline
\end{tabular}

Notes: *,**, and *** represent the level of significance at $1 \%, 5 \%$ and $10 \%$ respectively. The numbers inside parentheses are pvalues.

This study further examines whether CG code revision interval is a matter on firm value. Table 4 shows that CG code revision interval has significant negative relationship with firm value. This is consistent with hypothesis 2 arguing that longer interval of CG code revision may increase the cost of compliance with the new practices of governance which ultimately harms firm value. The possible reasons of decreasing in firm value may be due to the reluctance to comply with the massive new practices of CG which has long been accumulated, or may only selectively comply with the new practices which are less burden for the firms to follow.

Table 4: Regression Results on the Relationship between CG Code Revision Interval and Firm Value

\begin{tabular}{ccc}
\hline \hline FirmSize & $-0.2357 * * *$ & $-0.3070^{* * *}$ \\
Leverage & $(0.0000)$ & $(0.0000)$ \\
& $-0.5880 * * *$ & $-0.5405^{* * *}$ \\
Market-to-Book & $(0.0000)$ & $(0.0000)$ \\
ROE & $0.0709^{* * *}$ & $0.0713 * * *$ \\
& $(0.0000)$ & $(0.0000)$ \\
CGScore & $0.2107 * * *$ & $0.2299^{* * *}$ \\
& $(0.0342)$ & $(0.0000)$ \\
Interval_to_Revision & $0.1390^{* * *}$ & 0.0750 \\
& $(0.0030)$ & $(0.1327)$ \\
Interval_to_Revision ${ }^{2}$ & $-0.0743 * * *$ & $1.3462 * * *$ \\
& $(0.0000)$ & $(0.0000)$ \\
Constant & & $-0.9587 * * *$ \\
& & $(0.0000)$ \\
Firm Fixed Effect & $4.0172^{* * * *}$ & $3.8402^{* * *}$ \\
Standard Errors & $(0.000)$ & $(0.0000)$ \\
Obs & Yes & Yes \\
Adjusted R & Robust & Robust \\
Turning point & 15746 & 14772 \\
\hline \hline
\end{tabular}

Notes: $*, * *$ and $* * *$ represent the level of significance at $1 \%, 5 \%$ and $10 \%$ respectively. The numbers inside parentheses are $\mathrm{p}-$ values. Turning point is calculated from anti-logarithm of $\left(-1 \mathrm{x} \_b[\right.$ Interval_to_CurRevision] $) /\left(2 \mathrm{x} \_b\left[\right.\right.$ Interval_to_CurRevision $\left.\left.{ }^{2}\right]\right)$ 
Further analysis reveals that there is a significant nonlinear relationship between code revision interval and firm value. The squared of Interval_to_Revision is incorporated in the regression. The effect of Interval_to_Revision and Interval_to_Revision ${ }^{2}$ have significant relationships with firm value, but both estimates display the opposite effect. The nonlinear relationship is depicted in inverted U-shaped, drawing the pattern that increasing the interval of $\mathrm{CG}$ code revision improve firm value until to an extent that further increasing the interval backfire firm value. It implies that a moderate interval of CG code revision can optimally increase firm value. In other words, excessively long interval of CG code revisions deteriorate firm value, and excessively short interval of code revision does not optimally increase firm value. The turning point of the quadratic is calculated, which is fall to the interval of 4 years. It concludes that the best interval to revise the code of CG is 4 years once. In sum, the results give the notion that the interval of CG code revisions is significantly related to the effectiveness of CG code revisions. In fact, unwisely managing CG code revisions may not efficiently instill the new practices of governance to the firms to solve the existing agency problems.

\section{CONCLUSION}

This study investigate the effectiveness of the worlds' national codes of CG in improving firm value. The interval of code revision is highlighted in the investigation. This study argues that CG code revision interval is associated with the cost of compliance with the new practices of governance recommended through the revisions. This study first shows that progressive code revisions has significant positive effect on firm value. Further result shows that $\mathrm{CG}$ code revision interval is a matter to influence the effectiveness of the revisions. A nonlinear relationship is obtained between code revision interval and firm value. The nonlinear is depicted in inverted U-shaped relationship, indicating that excessively long interval of code revisions exerts opposite effect which harms firm value.

The findings of this study imply a practical implication that a moderate code revision interval, i.e. 4 years once, is the best timing to drive optimal firm value increment. For excessively long interval of code revision tends to accumulate a great number of new corporate governance guidance, the cost of compliance may be matter which lowers firm value. In such case, this study displays the limitation to directly account for the cost of compliance when assessing the effectiveness of CG code revisions. Nonetheless, this study gives the notion that firms' capability to adopt and adapt the new practices of governance is key to optimize the value to be generated from the newly revised code of CG. Hence, the policy makers need to tolerance with the capability of the majority firms either it is financially or nonfinancially when revising the code of CG. For the cost of compliance can hardly be assessed, the future study can associate the number of new guidance in each $\mathrm{CG}$ code revisions to firm value.

\section{ACKNOWLEDGEMENT}

The authors would like to extend their appreciation to the Universiti Sains Malaysia for the Research University Grant entitled "How Effective Corporate Governance Codes Revision Affects Firm Performance?” [Grant No. 1001/PMGT/816307] that makes this study and paper possible. 


\section{REFERENCES}

Aguilera, R. V., \& Cuervo-Cazurra, A. (2004). Codes of good governance worldwide: what's the trigger? Organization Studies, 25(3), 417-446.

Aguilera, R. V., Filatotchev, I., Gospel, H., \& Jackson, G. (2008). Contingencies, complementarities, and costs in CG models. Organization Science, 19(3): 475-92.

Anand, I. A. (2005). Voluntary vs mandatory Corporate Governance: Towards an optimal regulatory framework. American Law and Economics Association Annual Meetings Working Paper No. 44.

Australian Stock Exchange. (2003). Principles of Good Corporate Governance and Best Practice Recommendations. Australia: Australian Stock Exchange Ltd.

Becht, M., Bolton, P., \& Roell, A. (2003). Corporate Governance and Control. In G. M. Constantinides, M. Harris \& R. M. Stulz (Eds.), Handbook of Economics and Finance (pp. 1-86). North Holland: Elsevier.

Beiner, S., Drobetz, W., Schmid, M. M., \& Zimmermann, H. (2006). An integrated framework of Corporate Governance and firm valuation. European Financial Management, 12(2), 249-283.

Conyon, M. J., \& Mallin, C. (1997). A review of compliance with Cadbury. Journal of General Management, 22(3), 24-37.

Cuervo, A. (2002). Corporate governance mechanisms: A Plea for less code of good governance and more market control. Corporate Governance: An International Review, 10(2), 84-93.

Doidge, C., Karolyi, G. A., \& Stulz, R. (2007). Why do countries matter so much for Corporate Governance? NBER Working Paper 10726.

Drobetz, W., Schillhofer, A. \& Zimmermann, H. (2004). Corporate governance and expected stock returns: Evidence from Germany, European Financial Management, 10(2), 267-293.

Erhardt, O., \& Nowak, E. (2002). Die Durchsetzung von Corporate-Governance-Regeln. Die Aktiengesellschaft, 47(6), 336-345.

Fernández-Rodríguez, E., Gómez-Ansón, S., \& Cuervo-García, A. (2004). The stock market reaction to the Introduction of Best Practices Codes by Spanish firms. Corporate Governance: An International Review, 12(1), 29-46.

Garay, U., \& González, M. (2008). Corporate governance and firm value: the case of Venezuela. Corporate Governance, 16(3), 194-209.

Goncharov, I., Werner, J. R., \& Zimmermann, J. (2006). Does compliance with the German Corporate Governance code have an impact on stock valuation? An empirical analysis. Corporate Governance, 14(5), 432-445.

Hansmann, H., \& Kraakman, R. (2004). The End of History for Corporate Law. In J. N. Gordon \& M. J. Roe (Eds.), Convergence and Persistence in Corporate governance (pp. 33-68). Cambridge: Cambridge University Press.

Henry, D. (2010). Agency costs, ownership structure and corporate governance compliance: A private contracting perspective. Pacific-Basin Finance Journal, 18(1), 24-26.

Kouwenberg, R. R. (2008). Does voluntary corporate governance code adoption increase firm value in emerging markets? Evidence from Thailand. Mahidol University Working Paper Series.

La Porta, R., Lopez-de-Silanes, F., Shleifer, A., \& Vishny, R. W. (2000). Investor protection and corporate governance. Journal of Financial Economics, 58(1-2), 3-27.

Maassen, G. F., van den Bosch, F. A. J., \& Volberda, H. (2004). The Importance of disclosure in corporate governance self-regulation across Europe: A review of the Winter Report and the EU Action Plan. International Journal of Disclosure and Governance, 1(2), 146-159.

Munisi, G., \& Randøy, T. (2013). Corporate governance and company performance across Sub-Sahara African countries. Journal of Economics and Business, 70, 92-110. 
Pellens, B., Hillebrandt, F., \& Ulmer, B. (2001). Implementation of Corporate Governance-codes in German practice: An empirical analysis of the DAX 100 companies. Betriebs-Berater, 56, $1243-$ 50.

Scott, W. R. (1995). Institutions and Organizations. Thousand Oaks: SAGE Publications.

The Norwegian Corporate Governance Board. (2014). The Norwegian Code of Practice for Corporate Governance. Norway: The Norwegian Corporate Governance Board.

The Security Commission Malaysia. (2012). Malaysian Code on Corporate Governance 2012. Kuala Lumpur: Securities Commission Malaysia.

Weir, C., \& Laing, D. (2000). The performance-governance relationship: The effects of Cadbury Compliance on UK Quoted Companies. Journal of Management and Governance, 4(4), 265-281.

Zattoni, A., \& Cuomo, F. (2008). Why adopt codes of good governance? A comparison of institutional and efficiency perspectives. Corporate Governance, 16(1), 1-15. 